\title{
Does Body Mass Index Interfere in the Formation of Speech Formants?
}

\author{
Patricia Barbarini Takaki ${ }^{1}$ Marilena Manno Vieira ${ }^{1}$ Angelica Veiga Said ${ }^{1}$ Silvana Bommarito ${ }^{1}$ \\ ${ }^{1}$ Speach Therapy Departament, Universidade Federal de São Paulo, \\ São Paulo, SP, Brazil \\ Int Arch Otorhinolaryngol 2018;22:45-49.

\begin{abstract}
Address for correspondence Silvana Bommarito, Departamento de Fonoaudiologia, Universidade Federal de São Paulo, Rua Agostinho Rodrigues Filho, 350, apto 152 A, São Paulo, SP, 04026-040, Brazil (e-mail: bomarito@terra.com.br).
\end{abstract}

\begin{abstract}
Introduction Studies in the fields of voice and speech have increasingly focused on the vocal tract and the importance of its structural integrity, and changes in the anatomy and configuration of the vocal tract determine the variations in phonatory and acoustic measurements, especially in the formation of the formants (Fs). Recent studies have revealed the functional consequences arising from being overweight and having an accumulation of fat in the pharyngeal region, including obstructive sleep apnea syndrome (OSAS) and impacts on the voice.

Objectives To assess the relationship between body mass index (BMI) and analysis of the speech.

Methods This study was approved by the Ethics Committee of the Universidade Federal de São Paulo (no. 288,430). The cohort consisted of 124 individuals aged between 18 and 45 with full permanent dentition and selected randomly. The participants underwent a brief medical history taking, BMI assessments and recording emissions of the sustained vowels $|\mathrm{a} /,| \varepsilon /, \mid \mathrm{i} /$, and $/ \mathrm{u} /$ by acoustic program PRAAT (v. 5.3.85, Boersma and Weenink, Amsterdam, Netherlands). Recordings were taken using a unidirectional microphone headset (model Karsect HT-9, Guangdong, China), with a condenser connected to an external sound card (USB-SA 2.0, model Andrea, PureAudio $^{\mathrm{TM}}$, Pleasant Grove, UT, USA), to reduce noise.

Keywords

- adipose tissue

- body mass index

- pharynx

- speech

Results There was a significant correlation between BMI and formant 3 (F3) vowel /a/; however, there was a low degree of correlation intensity.

Conclusions We did not observe a correlation between the BMI and the speech formants, but we believe there is a trend in this correlation that leads to changes in speech patterns with increases in BMI.
\end{abstract}

\section{Introduction}

Studies in the fields of voice and speech have increasingly focused on the vocal tract and on the importance of its structural integrity. The vocal tract plays a very important role in the formation of speech sounds, amplifying certain harmonic groups, dampening others, and concentrating the resonance of the sound waves in specific parts of the vocal tract, according to individual configuration. ${ }^{1}$ This results in a

received

October 17, 2016

accepted

January 2, 2017

published online

April 19, 2017
DOI https://doi.org/ 10.1055/s-0037-1599131. ISSN 1809-9777. modification of the sound produced at the source, resulting in individual vocal characteristics.

For this reason, changes in the anatomy and configuration of the vocal tract determine the variations in phonatory and acoustic measurements, especially in the formation of the formants, which, according to Camargo and Cukier, cited by Gusmão, Campos and Maya, ${ }^{2}$ corresponds to the following: formant 1 (F1), opening of the mouth and the vertical displacement of the tongue; formant 2 (F2), horizontal
Copyright @ 2018 by Thieme Revinter Publicações Ltda, Rio de Janeiro, Brazil
License terms

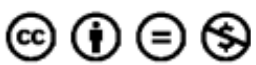


displacement of the tongue; and formant 3 (F3), anterior oral and pharyngeal cavities. ${ }^{2}$

There is an association between the length of the vocal tract and the average formant frequency; the longer the vocal tract, the lower the average formant frequency. ${ }^{1}$ This highlights the importance of understanding the factors that modify the vocal tract, and that may interfere in the quality of the voice and the precision of speech sounds.

Recent studies have revealed the functional consequences arising from being overweight and having fat accumulated in the pharyngeal region, including obstructive sleep apnea syndrome (OSAS) $)^{3,4}$ and impacts on the voice. ${ }^{5-7}$ The accumulation of adipose tissue, in addition to reductions in the diameter of the pharyngeal region, causes an endocrine reaction that increases the levels of free fatty acids accumulated in the skeletal muscles, consequently reducing muscular strength ${ }^{8,9}$ and the articulatory precision of the structures responsible for speech. ${ }^{10,11}$

Since there are few studies in the literature on this topic, we aimed to assess the relationship between body mass index (BMI) and the analysis of the speech formants to verify if the BMI is an important factor in the integrity of the vocal tract, and if an increase in the BMI generates changes in formant patterns.

\section{Methods}

This study was approved by the Ethics Committee of the Universidade Federal de São Paulo (no. 288,430), and received funding from the Brazilian Coordination for the Improvement of Higher Education Personnel (CAPES, in the Portuguese acronym) for its development. All volunteers agreed to the study and provided written informed consent.

A total of 124 individuals aged between 18 and 45 years (average age: 22 years) from São Paulo participated in the study. Subjects with full permanent dentition were selected randomly, regardless of their BMI. Individuals with alcohol or tobacco habits, syndromes or malformations, physical or mental deficiencies, or who suffered cranioencephalic trauma or underwent surgical procedures to the head or neck, and those with orofacial myofunctional alterations were excluded.

\section{Experimental Procedure}

All procedures were performed at the Orofacial Myotherapy Clinic at the Universidade Federal de São Paulo. Each individual received precise, detailed, and consistent instructions on all the procedures and evaluations. All instruments used for the evaluations were cleaned with $70 \%$ alcohol after each procedure for biosafety reasons. All individuals underwent a brief anamnesis to obtain personal information. Their BMI and speech formants were then evaluated as detailed below.

\section{Evaluation of Body Mass Index}

The BMI comprises the coefficient of the weight by the square of the height, and was created by Quetelet ${ }^{12}$ (-Table 1 ). Weight (in $\mathrm{kg}$ ) was obtained using a digital scale; each
Table 1 Body Mass Index Classification ${ }^{12}$

\begin{tabular}{|l|l|}
\hline Degree of obesity & BMI value $\left(\mathrm{kg} / \mathrm{m}^{2}\right)$ \\
\hline Normality & $20.0-25.0$ \\
\hline Obesity class I & $25.1-29.9$ \\
\hline Obesity class II & $30.0-34.9$ \\
\hline Obesity class III & $35.0-39.9$ \\
\hline Obesity class IV & $\geq 40.0$ \\
\hline
\end{tabular}

Abbreviation: BMI, body mass index.

individual, wearing light clothing, was positioned with their backs and heads straight in the Frankfurt horizontal plane, feet barefoot and parallel, and placed in the middle of the platform of the device. All individuals were positioned in the same manner to obtain height measurements, with the use of a stadiometer.

\section{Analysis of Speech Formants}

Each individual was seated with the head and back comfortably erect. Recordings were taken using a unidirectional microphone headset (model Karsect HT-9, Guangdong, China), with a condenser connected to an external sound card (USB-SA 2.0, model Andrea, PureAudio ${ }^{\mathrm{TM}}$, Pleasant Grove, UT, USA) to reduce noise and avoid potential problems with system sound compatibility. The microphone was fixed and positioned correctly on the pinna of the participants at a distance of $5 \mathrm{~cm}$ from the mouth and at a deviation of $45^{\circ}$ from the midline, determined by the philtrum. All tasks were recorded and stored through the acoustic program PRAAT (v. 5.3.85, Boersma and Weenink, Amsterdam, Netherlands), installed on a Lenovo Yoga 213 computer.

Emissions of the sustained vowels /a/, / $/ \varepsilon /$, /i/, and /u/ were recorded, and participants were instructed to produce them at the same intensity of normal speech, to inhale deeply, produce the requested vowel, and to sustain it for as long as possible. A spectrographic analysis was then performed, and the values of the first three formants (F1, F2, and F3) were extracted. These express, in frequencies, the vowels of speech according to the configuration of the vocal tract, with F1 being the expression of the opening of the mouth and the vertical displacement of the tongue, F2 being the horizontal displacement of the tongue, and F3 being the anterior oral and pharyngeal cavities. ${ }^{2}$

\section{Data Analysis}

Data were statistically analyzed using parametric tests; a significance level of 0.05 (5\%) and a statistical reliability of $95 \%$ were adopted, with $p$ values recorded for all the results. Variable data were expressed in percentages. Pearson correlation test was used to measure the correlation between variables. When positive values were recorded, the correlation between variables was positive; when negative values were produced, the relationship was inversely proportional. The degree of correlation intensity was determined by the classification scale presented in -Fig. 1. 


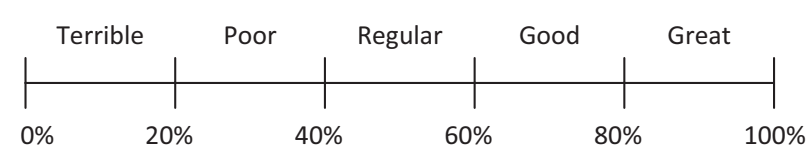

Fig. 1 Classification scale.

\section{Results}

The study sample was divided by sex, and the distribution of individuals with BMIs classified as normal and obese was analyzed. The BMI and sex distributions are presented in - Table 2. By grouping obese classifications for men, the number of individuals with a normal BMI was equal to that of obese individuals, while for women, the number of obese individuals was $32 \%$ lower. There was a greater number of women with normal BMIs than men, but a lower number of women with BMIs classified as obese compared with men.

To assess the relationship between BMIs and speech formants, their correlation was determined ( - Table 3 ). There was a significant correlation between BMI and F3 /a/ $(p<0.05)$; however, there was a low degree of correlation intensity, consequently making this an irrelevant finding. There was no significant correlation between BMI and speech formants in the sample studied.

\section{Discussion}

Overweight individuals have elevated amounts of adipose tissue in all body structures, with the pharyngeal region being one of the most affected. ${ }^{3-7}$ This accumulation results in several factors that undermine the proper functioning of structures. For example, a reduction in the pharyngeal diameter, or the velopharyngeal area, is highly associated with the possibility of collapse of the upper airways in cases of OSAS. ${ }^{4,10,11}$ An increase in soft tissue can also occur in the region, and tissues that collapse and interrupt the flow of air $^{4,10,11}$ may result in vocal changes through the increase in vibration during phonation, causing noises, instability, and changes to the focus of resonance. ${ }^{6,7}$ In addition, an increase in the amount of adipose tissue in the abdominal region increases Pcrit by 1.0 and $1.7 \mathrm{~cm} \mathrm{H}_{2} \mathrm{O}$ per $10 \mathrm{~kg} / \mathrm{m}^{2}$ of body mass index for women and men, respectively. Increased fat deposition around the pharynx and narrowing of the airways may increase the pressure of the extra-extensive tissue and increase the collapsibility of the upper airways. ${ }^{10}$

Table 2 Sample distribution by sex and BMI class

\begin{tabular}{|c|c|c|c|c|c|c|c|c|}
\hline \multirow{2}{*}{\multicolumn{2}{|c|}{ BMI }} & \multicolumn{3}{|c|}{ Male } & \multicolumn{3}{|c|}{ Female } & \multirow[t]{2}{*}{ Total } \\
\hline & & $N$ & $\%$ & Mean & $\mathrm{N}$ & $\%$ & Mean & \\
\hline \multicolumn{2}{|l|}{ Normal } & 34 & $27 \%$ & 22.16 & 38 & $31 \%$ & 21.47 & 72 \\
\hline \multirow[t]{5}{*}{ Obese } & Class I & 26 & $21 \%$ & 27.29 & 14 & $11 \%$ & 27.10 & 40 \\
\hline & Class II & 7 & $6 \%$ & 32.18 & 4 & $3 \%$ & 31.91 & 11 \\
\hline & Class III & 1 & $1 \%$ & 37.72 & 0 & $0 \%$ & 0.00 & 1 \\
\hline & Class IV & 0 & $0 \%$ & 0.00 & 0 & $0 \%$ & 0.00 & 0 \\
\hline & TOTAL & 68 & $55 \%$ & 23.87 & 56 & $45 \%$ & 16.10 & 124 \\
\hline
\end{tabular}

Abbreviation: BMI, body mass index.

Table 3 Correlation of BMI with speech formants 1, 2, and 3, and vowels /a/, /i/, and /u/, according to sex

\begin{tabular}{|c|c|c|c|c|}
\hline \multirow[t]{3}{*}{ Formants } & \multicolumn{4}{|l|}{ BMI } \\
\hline & \multicolumn{2}{|l|}{ Men } & \multicolumn{2}{|l|}{ Women } \\
\hline & Correlation (r) & $p$ value & Correlation (r) & $p$ value \\
\hline $\mathrm{F} 1 / \mathrm{a} /$ & $-22.50 \%$ & 0.065 & $8.10 \%$ & 0.551 \\
\hline $\mathrm{F} 2 / \mathrm{a} /$ & $17.30 \%$ & 0.158 & $16.50 \%$ & 0.224 \\
\hline $\mathrm{F} 3 / \mathrm{a} /$ & $24.40 \%$ & 0.045 & $-15.60 \%$ & 0.252 \\
\hline $\mathrm{F} 1 / \mathrm{i} /$ & $-12.10 \%$ & 0.325 & $15.20 \%$ & 0.264 \\
\hline $\mathrm{F} 2 / \mathrm{i} /$ & $-3.60 \%$ & 0.771 & $-2.10 \%$ & 0.877 \\
\hline $\mathrm{F} 3 / \mathrm{i} /$ & $12.00 \%$ & 0.657 & $8.10 \%$ & 0.648 \\
\hline $\mathrm{F} 1 / \mathrm{u} /$ & $-14.70 \%$ & 0.233 & $23.70 \%$ & 0.079 \\
\hline $\mathrm{F} 2 / \mathrm{u} /$ & $-0.30 \%$ & 0.979 & $-2.30 \%$ & 0.865 \\
\hline $\mathrm{F} 3 / \mathrm{u} /$ & $8.50 \%$ & 0.494 & $-2.10 \%$ & 0.878 \\
\hline
\end{tabular}

Abbreviations: BMI, body mass index; F, formant. 
Furthermore, adipose tissue causes an endocrine reaction that increases the levels of free fatty acids accumulated in the skeletal muscles, reducing muscle strength ${ }^{8,9}$ and the articulatory precision of the structures responsible for speech.

The amount of tissue that vibrates during phonation is related to the fundamental frequency $\left(\mathrm{F}_{0}\right)^{12}$ and voice resonance, ${ }^{6,7}$ and obese individuals have voice complaints related to the phonatory effort. ${ }^{7,13}$ This may strongly suggest an imbalance in the phonatory system due to fatty deposits in the vocal tract. ${ }^{6}$ The numerical analysis of the formants portrays the configuration of the vocal tract and its adaptations. It mainly expresses vowels, and it is responsible for the distinction between them. ${ }^{1,2}$ In order to better understand how this analysis works, it is helpful to consider some physical concepts of sound waves.

Sound waves are formed by periodic vibrating movements caused by the variation in air pressure exerted by the sound source, which in this case is the vocal cords. All sound waves possess the physical properties of frequency, intensity, and timber, with the latter comprising the sound wave. ${ }^{14}$ After formation, they pass through the vocal tract, a structure consisting of muscles and mucosa, and undergo a process of "modeling," in which waves are reflected and dampened throughout the tract, causing the absorption of some waves and the amplification of others. ${ }^{1}$ This reflection of waves causes a secondary movement in the structures of the vocal tract, provoking resonance, the vibration of two or more bodies at the same frequency. ${ }^{14}$

Therefore, by analyzing a sound by its spectrum, we find that $F_{0}$ is the lowest frequency of the series of sinusoidal waves reverberated through the vocal tract, and every integer multiple of $F_{0}$ is what we know as formants or harmonic frequencies, with $2 \mathrm{~F}_{0}, 3 \mathrm{~F}_{0}, 4 \mathrm{~F}_{0}$, and $5 \mathrm{~F}_{0}$ referred to as F1, F2, F3, and F4 respectively. ${ }^{14}$ These are interpreted as parts of the vocal tract, according to their highest concentration and speech expression. ${ }^{1,2}$

In our study, despite the low intensity of the correlation, $\mathrm{BMI}$ and $\mathrm{F}^{2}$ were found to be directly proportional. The low degree of correlation may be due to the low participation of obese individuals of classes III and IV, a limitation of this study. Therefore, the correlation was identified statistically, but could not be confirmed.

However, there were strong quantitative and objective indications of the effects of obesity on the formation of F3. These findings demonstrate that frequencies concentrated in the pharyngeal cavity are more acute, even in the region where there are greater deposits of adipose tissue according to the literature. , $^{4,10,11}$ We believe that this tissue is more susceptible to vibration in concordance with the higher frequencies of the vocal cords and, therefore, has more vibration cycles per second, increasing the frequency of F3.

These findings reinforce earlier studies on functional changes; $3,4,6-12$ these changes may compromise the respiratory, $3,4,7,10$ phonatory, 6,7,12,13 and speech patterns. Our results agree with those of González ${ }^{15}$ and Hamdan, ${ }^{16}$ who showed that the correlation between the BMI and the speech formants was weak. However, it is worth stressing the limitation of our study in relation to the sample distribution between classes of obesity. Future studies should consider counteracting this limitation.

For clinical application, we believe that the imbalance of the phonatory system in obese individuals not only causes complaints related to phonatory effort, but also a reduction in movement precision due to an endocrine reaction, ${ }^{8,9}$ and changes in phonatory patterns ${ }^{6}$ (with the exception of acoustic voice measurements independent from the vocal tract ${ }^{17}$ ) and in the focus of resonance. These deposits represent physical and structural limitations on voice rehabilitation, with a reduction in BMI as a conditional factor for therapeutic improvement, although the minimum weight loss required for fat reduction in the pharyngeal region is yet unknown.

In the case of patients with OSAS, therapy should be interpreted in the same manner, because the accumulation of adipose tissue represents a physical and structural limitation on rehabilitation. This results in the following questions: at which BMI do functional impairments begin to occur, and what is the weight loss required for a functional improvement? A recent study attempted to address these questions, and found that a BMI reduction of 7.23 points was insufficient to show an effect. ${ }^{18}$ Therefore, we emphasize the importance of continuing this line of research to allow for a more precise treatment.

Finally, we suggest that additional studies be performed to understand the physical phenomena of sound waves in relation to muscle and adipose tissue, in an attempt to understand the mechanical differences of the wave as it passes through the vocal tract lined by each of these tissues. This understanding will provide a broader view of the effects of adipose tissue accumulation in the pharynx and its functional consequences, not only in terms of reducing pharyngeal space, but also the increased susceptibility to vibration and collapse, in the case of OSAS.

\section{Conclusion}

In this study, we did not observe a correlation between BMI and speech formants, but believe there is a trend in this correlation leading to changes in speech patterns with increases in BMI.

\section{References}

1 Fant G. Acoustic Theory of Speech Production: With calculations based on x-ray studies of Russian articulations. The Hague: Paris; 1970

2 Gusmão CS, Campos PH, Maia ME. O formante do cantor e os ajustes laríngeos utilizados para realizá-lo: uma revisão descritiva. Per Musi. 2010;21:43-50

3 Shelton KE, Woodson H, Gay S, Suratt PM. Pharyngeal fat in obstructive sleep apnea. Am Rev Respir Dis 1993;148(02): 462-466

4 Mortimore IL, Marshall I, Wraith PK, Sellar RJ, Douglas NJ. Neck and total body fat deposition in nonobese and obese patients with sleep apnea compared with that in control subjects. Am J Respir Crit Care Med 1998;157(01):280-283

5 Halum SL, Postma GN, Johnston C, Belafsky PC, Koufman JA. Patients with isolated laryngopharyngeal reflux are not obese. Laryngoscope 2005;115(06):1042-1045 
6 da Cunha MG, Passerotti GH, Weber R, Zilberstein B, Cecconello I. Voice feature characteristic in morbid obese population. Obes Surg 2011;21(03):340-344

7 Souza LB, Pereira RM, Santos MM, Godoy CM. Fundamental frequency, phonation maximum time and vocal complaints in morbidly obese women. Arq Bras Cir Dig 2014;27(01):43-46

8 Eckardt K, Taube A, Eckel J. Obesity-associated insulin resistance in skeletal muscle: role of lipid accumulation and physical inactivity. Rev Endocr Metab Disord 2011;12(03):163-172

9 Stenholm S, Sallinen J, Koster A, et al. Association between obesity history and hand grip strength in older adults-exploring the roles of inflammation and insulin resistance as mediating factors. J Gerontol A Biol Sci Med Sci 2011;66(03):341-348

10 Pham LV, Schwartz AR. The pathogenesis of obstructive sleep apnea. J Thorac Dis 2015;7(08):1358-1372

11 Horner RL, Mohiaddin RH, Lowell DG, et al. Sites and sizes of fat deposits around the pharynx in obese patients with obstructive sleep apnoea and weight matched controls. Eur Respir J 1989; 2(07):613-622
12 Quetelet A. Sur l'homme et le développement de ses facultés. 1st ed. Paris: Fayard; 1835

13 de Souza LB, Pernambuco LdeA, dos Santos MM, da Silva JC. Vocal complaint, auditory-perceptual assessment of voice and vocal self-assessment in women with morbid obesity. Arq Bras Cir Dig 2015;28(Suppl 1):23-25

14 Fernandes JC. Acústica e ruídos - Apostila do Laboratório de Acústica e Vibrações (LAV) da Faculdade de Engenharia - UNESP. Bauru: Depto. de Eng ${ }^{\mathrm{a}}$ Mecânica - UNESP, 2012

15 González J. Formant frequencies and body size of speaker: a weak relationship in adult humans. . J Phonetics 2004;32(02):277-287

16 Hamdan AL, Al Barazi R, Khneizer G, et al. Formant frequency in relation to body mass composition. J Voice 2013;27(05):567-571

17 Franco D, Fragoso I, Andrea M, Teles J, Martins F. Somatotype and body composition of normal and dysphonic adult speakers. J Voice 2017;31(01):e9-e21

18 Hamdan AL, Safadi B, Chamseddine G, Kasty M, Turfe ZA, Ziade G. Effect of weight loss on voice after bariatric surgery. J Voice 2014; 28(05):618-623 